\title{
Physical activity and cognitive function in individuals over 60 years of age: a systematic review
}

This article was published in the following Dove Press journal:

Clinical Interventions in Aging

12 April 2014

Number of times this article has been viewed

\author{
Ashley Carvalho',2 \\ Irene Maeve Rea ${ }^{2}$ \\ Tanyalak Parimon ${ }^{3,4}$ \\ Barry J Cusack ${ }^{3,5}$
}

'Department of Public Health, ${ }^{2}$ School of Medicine, Dentistry and Biomedical Science, Queen's University Belfast, Northern Ireland, UK; ${ }^{3}$ Research and Development Service, Veterans Affairs Medical Center, Boise, ID, USA; ${ }^{4}$ Division of Pulmonary and Critical Care Medicine, ${ }^{5}$ Division of Gerontology and Geriatric Medicine, Department of Medicine, University of Washington, Seattle, WA, USA

Correspondence: Ashley Carvalho School of Medicine, Dentistry and Biomedical Science, Queen's University Belfast, Northern Ireland, UK BT9 7BL Email acarvalho0I@qub.ac.uk
Background: It is unclear whether physical activity in later life is beneficial for maintenance of cognitive function. We performed a systematic review examining the effects of exercise on cognitive function in older individuals, and present possible mechanisms whereby physical activity may improve cognition.

Methods: Sources consisted of PubMed, Medline, CINAHL, the Cochrane Controlled Trials Register, and the University of Washington, School of Medicine Library Database, with a search conducted on August 15, 2012 for publications limited to the English language starting January 1, 2000. Randomized controlled trials including at least 30 participants and lasting at least 6 months, and all observational studies including a minimum of 100 participants for one year, were evaluated. All subjects included were at least 60 years of age.

Results: Twenty-seven studies met the inclusion criteria. Twenty-six studies reported a positive correlation between physical activity and maintenance or enhancement of cognitive function. Five studies reported a dose-response relationship between physical activity and cognition. One study showed a nonsignificant correlation.

Conclusion: The preponderance of evidence suggests that physical activity is beneficial for cognitive function in the elderly. However, the majority of the evidence is of medium quality with a moderate risk of bias. Larger randomized controlled trials are needed to clarify the association between exercise and cognitive function and to determine which types of exercise have the greatest benefit on specific cognitive domains. Despite these caveats, the current evidence suggests that physical activity may help to improve cognitive function and, consequently, delay the progression of cognitive impairment in the elderly.

Keywords: exercise, cognitive function, elderly

\section{Introduction}

An unprecedented growth of the aging population is taking place. For example, in $2000,28 \%$ of adults aged 65 and older were expected to reach at least 90 years; this number is projected to rise to $47 \%$ by 2050 , representing a near-doubling of the elderly population to 80 million. ${ }^{1}$ The economic impact of an aging population on health care systems is potentially overwhelming, in particular for age-related disorders such as dementia. In 2005, approximately 29.3 million individuals with dementia incurred a cost of US\$315 billion worldwide, with the highest costs in North America and Europe. ${ }^{2}$ Since then, the global prevalence of dementia has increased to more than 34 million, and the bulk of disease burden is shifting from developed to developing countries. ${ }^{3}$ As such, effective interventions to help reduce the prevalence of cognitive disability in the elderly are needed. One possible intervention that deserves 
consideration is physical activity, an adjunct that has many well established health benefits and may serve to enhance quality of life. ${ }^{4}$ However, the effect of exercise on cognitive function remains controversial. A National Institutes of Health conference review of age-related cognitive decline reported a marginal benefit of exercise in one small randomized controlled trial (RCT) and eight observational studies showing a possible decrease in cognitive decline with exercise. ${ }^{4}$ A Cochrane review of eleven randomized clinical trials reported that aerobic exercise improved cognition in a few domains, including cognitive speed and auditory/ visual attention, in subjects without cognitive impairment. ${ }^{5}$ Another Cochrane review of exercise in patients with dementia found only two relevant studies and concluded that there was insufficient evidence of benefit from exercise in these patients. ${ }^{6}$ These reviews did not find sufficient evidence to endorse exercise as beneficial to cognition, but were, overall, narrow in scope. However, other reviews have determined different results; for example, a more recent review concluded that an exercise regimen of one hour at least 3 times per week for 6 weeks was beneficial in subjects with or without cognitive impairment. ${ }^{7}$ We have performed a systematic review to assess the validity of the current data, including more recent randomized clinical trials and observational studies that provide a broad-based view of the effect of exercise on cognition in elderly persons.

\section{Materials and methods Studies}

All RCTs with at least 30 participants and lasting at least 6 months, and all observational studies (prospective cohort studies, case-control studies, and longitudinal studies) with at least 100 participants and lasting at least one year, which were published in the English language on or after January 1, 2000 until August 15, 2012, and met the inclusion criteria were considered (Table 1).

\section{Participants}

Only participants who were 60 years or older were included in this review. Studies examining the effects of physical activity in elderly individuals with or without mild cognitive impairment or cognitive disease (such as Alzheimer's disease or other dementia) were included. Studies including participants with systemic disorders such as chronic obstructive pulmonary disease or diabetes, those with traumatic brain injury, or comorbidities that precluded participation in exercise programs were excluded.
Table I Characteristics of included studies

\begin{tabular}{lll}
\hline Parameters & $\begin{array}{l}\text { Number of } \\
\text { studies }\end{array}$ & References \\
\hline $\begin{array}{l}\text { Type of included studies } \\
\text { Randomized controlled trial }\end{array}$ & 10 & $8-10,17-21,26,27$ \\
$\begin{array}{l}\text { Prospective cohort } \\
\text { Case-control }\end{array}$ & 15 & $11-16,22-24,55-60$ \\
$\quad 1$ & 61 \\
Observational & 1 & 62 \\
Overall quality of included studies & & \\
Good & 9 & $9,10,14,17-22$ \\
Fair & 15 & $8,11-13,15,23,26,27$, \\
& & $55-58,60-62$ \\
$\quad$ Poor & 3 & $16,24,59$ \\
Overall risk of bias in included studies & \\
Low & 8 & $9,10,14,17,18,20-22$ \\
Moderate & 16 & $8,11-13,15,19,23,26$, \\
& & $27,55-58,60-62$ \\
High & 3 & $16,24,59$ \\
\hline
\end{tabular}

\section{Interventions}

Physical activity was considered to be any aerobic or isometric exercise of any intensity, duration, or frequency that aimed to improve overall physical fitness. For randomized clinical trials, active interventions such as aerobic exercise, isometric exercise, health education programs with monitored exercise sessions, or physical therapy-driven exercise treatments were compared with control groups that received no intervention (Table 2).

\section{Outcome measures}

The primary outcome measurement was cognitive function. The most commonly used tests included the Mini-Mental State Examination (MMSE) or Modified Mini-Mental State Examination (3MS), both of which give a global measure of cognitive function, and the Cognitive Ability Screening Instrument (CASI), which indicates the presence or absence of dementia (Table 2). A neuropsychological test battery with published criteria (such as the Mayo Clinic Criteria for dementia) utilized by an expert panel in diagnosing the presence or absence of dementia was also accepted.

\section{Search methods for study identification}

We searched PubMed, Medline, CINAHL, the Cochrane Controlled Trials Register, and the University of Washington School of Medicine Library database on August 15, 2012 for studies published in English on or after January 1, 2000. We used MeSH terms to find studies of physical activity including: adaptation, physiological/physiology*, exercise/ physiology*, and physical fitness/physiology*. To reduce our 
findings to studies that measured cognition or incidence of cognitive disease and physical fitness, we searched using the following MeSH terms: cognition, cognitive disease, cognition disorders/prevention and control, cognition/physiology*, brain/physiology*, memory/physiology*, motor activity/ physiology*, neuropsychological tests, dementia, and Alzheimer's disease. To further reduce our findings to studies that focused on elderly human subjects, we searched using the MeSH terms: humans, elderly, aged, aging, old, older, and geriatric.

\section{Data collection}

Two reviewers screened the titles and abstracts of all studies identified by the search ( 71 studies) and irrelevant studies were excluded. Relevant papers were then assessed in full for inclusion eligibility.

\section{Quality assessment}

Two reviewers assessed the methodological quality of the selected studies. The Agency for Healthcare Research and Quality Methods Reference Guide for Effectiveness and Comparative Effectiveness Reviews was used to perform quality assessment of the trials. These criteria include information on sampling method, outcome measurement, intervention, and reporting of biases and limitations. A summary of these criteria is presented in Table S1.

\section{Results}

\section{Description of studies}

Seventy-one studies were identified using the database as described in the Materials and methods section. After removal of duplicates, 57 full-text articles were assessed for eligibility (Figure 1). Thirty studies were excluded, leaving 27 studies that were eligible for review according to the prespecified criteria (Figure 1). A total of 30,572 subjects over 60 years of age were included in the 27 studies that met our inclusion criteria. The characteristics of the studies included in this review are described in Tables 1, 2, and 3. The 30 excluded studies are described in Table S2.

\section{Type of included studies, and quality and bias}

Fifteen prospective cohorts, ten RCTs, one case-control study, and one observational study met the criteria for review (Table 1). Eight studies were considered to be of high quality. One study, ${ }^{8}$ an RCT, was considered to be of fair quality, rather than high, because approximately $12 \%$ of patients dropped out

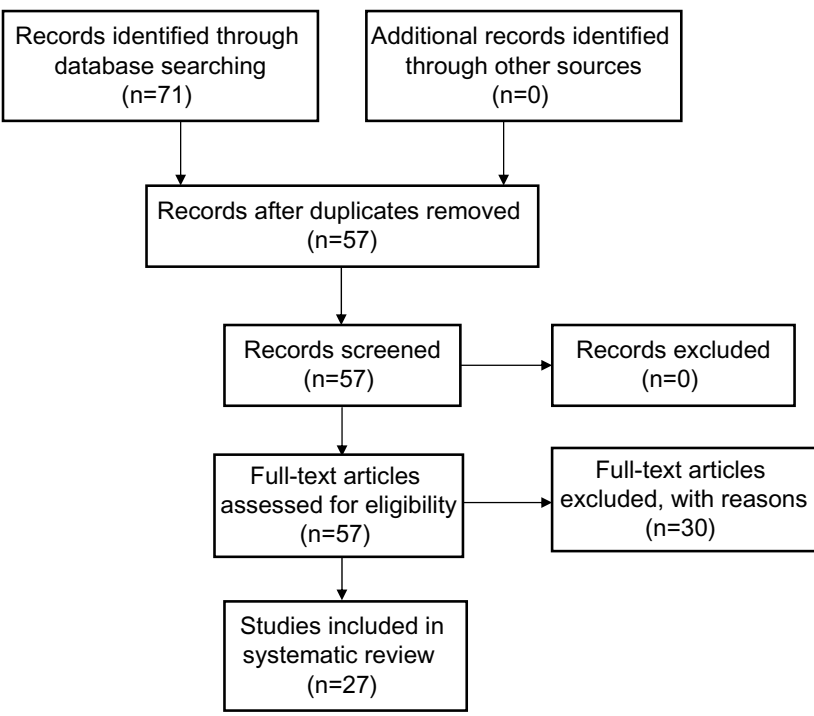

Figure I Description of studies which were identified, screened, and included in the systematic review.

of the study and could not be assessed. The majority of studies $(15 / 27)$ were of fair quality while three were considered poor quality. The overall risk of bias was moderate for the majority of the studies (16/27) with eight considered low risk and three at high risk of bias (Table 1). Seven of ten RCTs included in the review were generally of higher quality and exhibited lower bias overall (Table 1). However, the RCT evidence included in this review displayed potential bias in the form of lack of allocation concealment and lack of assessor blinding, as well as lack of participant blinding, since participants were randomized into either a physical activity group or an education/ noninterventional control group. In these studies, the evidence tended to be of lower quality with potentially higher bias due to possible unreliable self-reporting, potential influence of interviewers, and use of questionnaires and interviews to assess physical activity rather than direct measurements.

\section{Selection bias}

Most of the studies included in this review were at risk of selection bias, because the participants were largely drawn from specific population samples (hospital, city, region). Selection bias may also have occurred due to the fact that the decision to partake in physical activity may be linked to potentially confounding lifestyle choices. Further, followup visits were required for most of the studies, and would require the ability to commute to study centers. Potential participants were excluded if they had chronic disease, such as cardiovascular disease, pulmonary disease, diabetes, physical disability, or depression. Therefore, the study data cannot be extrapolated to such individuals. 
Table 2 Design, methods, interventions and assessment, and outcome measures in included studies

\section{Source and study design}

Buchman et $\mathrm{al}^{22}$ Prospective study

Bixby et al $^{62}$ Observational

Cassilhas et $\mathrm{al}^{18}$ RCT

Geda et $\mathrm{al}^{61}$ Case-control

Klusmann et al ${ }^{10}$ RCT

Busse et $\mathrm{al}^{17}$ RCT

\section{Methods}

Total daily physical activity was measured with actigraphs at baseline. Late-life physical, social, and cognitive activities were assessed by self-report and by the 1985 National Health Interview Survey questions at baseline and follow-up.

Follow-up: annual assessment for $3.5 \pm \mathrm{I} .54$ years

Participants were randomized to a control group $(n=14)$ or a treatment group $(n=17)$.

Cognitive status was assessed at baseline and followup using a neurocognitive test battery. Neither the participants nor the outcome assessors were blinded, and the use of allocation concealment is unclear. Follow-up: 3, 6, and 9 months

Participants were recruited from a retirement community through posted flyers, closed-circuit television announcements, and investigator presentations.

Physical activity levels were assessed using the YPAS. Cognitive and inhibitory executive function was assessed by the Stroop Color and Word Test. Follow-up: not applicable

Participants were randomized to 3 groups: a control group $(n=23)$, moderate exercise group $(n=19)$, and high exercise group $(n=20)$.

Use of blinding and allocation concealment in the study is unclear.

Physical fitness was assessed at baseline and follow-up by the one RM test.

Cognitive status was assessed at baseline and follow-up using a neuropsychological test battery.

Follow-up: 24 weeks

Participants underwent stratified random sampling in to case or control group.

Physical fitness was assessed through self-reporting at baseline.

Cognitive status was assessed at baseline and follow-up using a neuropsychological test battery and visuospatial skills.

Follow-up: 4 years

This study enrolled German-speaking women from Berlin. Eligible subjects were randomized into 2 intervention groups ( $\mathrm{n}=91$ for exercise group, $\mathrm{n}=92$ for computer group), and a control group ( $n=76)$.

12 participants ( 5 in the exercise group and 7 in the computer group) refused to participate after being informed about their group assignment and withdrew consent before treatment started.

A complete neuropsychological assessment and physical evaluation at baseline and 6 months. Follow-up: 6 months

\section{Participants}

716 subjects

I 14 males and 602 females

$81.6 \pm 7.12$ years

Inclusion criteria: eligible participants of Rush Memory and Aging Project.

Exclusion criteria: Presence of clinical AD dementia and non-AD dementia; unable to have at least one follow-up cognitive testing 3 I subjects

8 males and 23 females

62-86 years

Inclusion criteria: No programmed physical exercise 6 months prior to selection; subjective memory complaints; normal GDS and MMSE; changes in objective memory test; preserved function in instrumental and basic activities of daily living.

Exclusion criteria: dementia, depression, anxiety disorders, head trauma or stroke within one year, substance abuse, unstable cardiovascular disease

120 subjects

38 males and 82 females

65-92 years

Retirement community residents recruited through posted flyers, closed-circuit television announcements, and investigator presentations.

Inclusion criteria: above average intelligence; stable patterns of physical activity during a 3-5-year period before the study.

Exclusion criteria: depression, dementia

62 subjects

All males

65-75 years

Inclusion criteria: not described.

Exclusion criteria: cardiovascular disease; psychiatric conditions; use of psychotropic drugs; $<8$ years of schooling; dementia (MMSE score $<23$ )

I,324 subjects

681 males and 633 females

70-89 years

Participants of the Mayo Clinic Study of Aging

Cases: $(n=198)$ cases with mild cognitive impairment based on: concern expressed by a physician or nurse; cognitive impairment in one or more tested domains; ability to participate in normal functioning activities; and free of dementia.

Controls: $(n=I, 126)$ cases with normal cognitive function according to published normative criteria for the community 259 subjects

All female

Age $>70$ years

Eligibility criteria: being unfamiliar with the computer and exercising less than one hour per week.

Exclusion criteria: severe visual or hearing impairment; a previous or current diagnosis of depression or psychosis; any other neurological or medical disorder that would interfere with cognitive performance or preclude successful participation in the intervention programs 
Interventions

None

Treatment group: a one-hour biweekly training session for 9 months with 6 resistance-training exercises per session. Loads progressively increased in series of 12,10 , and 8 repetitions.

Control group: no intervention

\section{None}

Physical fitness assessment: YPAS and weekly energy expenditure (beyond basal metabolic rate).

Stability in physical activity levels for 3-5 years prior to the study assessment: a health history questionnaire.

Cognitive function assessment: Kaufman Brief Intelligence Test and Stroop Color and Word Test

Moderate exercise group: Three one-hour sessions/week (10-minute cycling warm-up, stretching exercises and weight training using loads of $50 \%$ of one RM and alternating segments with two series of 8 repetitions for each segment).

High exercise group: Three one-hour sessions/week (10-minute cycling warm-up, stretching exercises, and weight training using loads of $80 \%$ of one RM and alternating segments with two series of 8 repetitions for each segment).

Control group: one weekly training session consisting of warm-up and stretching exercises, but no overload training

\section{None}

Physical fitness assessment: a self-reported questionnaire derived from the 1985

National Health Interview Survey and the Minnesota Heart Survey intensity codes.

Cognitive function assessment: Mayo Clinic criteria for mild cognitive impairment

Exercise group: exercise program consisted of aerobic endurance, strength, and flexibility training, as well as practice of balance and coordination.

Computer group: heterogeneous and multifaceted themes including creative matters, coordinative and memory tasks, eg, operating with the common software and hardware, writing, playing, calculating, surfing on the Internet, emailing, drawing, image editing, and videotaping.

Control group: continued their habitual life
Cognitive function measurements

A computer-scoring battery of 19 tests

Diagnosis of $A D$ and non-AD was performed by clinicians using National Institute of Neurological and Communicative Disorders, Stroke-Alzheimer's Disease and Related Disorders Association Criteria

Rivermead Behavioral Memory Test

Wechsler Adult Intelligence Scale

Direct and Indirect Digit Span

Memory Complaints Scale

Cambridge Cognitive Test

Kaufman Brief Intelligence Test Stroop Color and Word Test

Wechsler Adult Intelligence Scale III Wechsler Memory Scale-Revised

Toulouse-Pieron concentration attention test Ray-Osterrieth complex figure

Mayo Clinic criteria for mild cognitive impairment

Neuropsychological assessment

RBMT, FCSRT, TMT, and Stroop Test 
Table 2 (Continued)

\begin{tabular}{|c|c|}
\hline $\begin{array}{l}\text { Source and } \\
\text { study design }\end{array}$ & Methods \\
\hline $\begin{array}{l}\text { Ku et al" } \\
\text { Prospective study }\end{array}$ & $\begin{array}{l}\text { Physical activity and activities of daily living were } \\
\text { assessed through questionnaires. The survey was } \\
\text { conducted every 3-4 years from } 1996 \text { to } 2007 . \\
\text { Cognitive performance was assessed using the } \\
\text { I0-item SPMSQ. } \\
\text { Follow-up: I I years }\end{array}$ \\
\hline $\begin{array}{l}\text { Larson et } \text { al }^{55} \\
\text { Prospective study }\end{array}$ & $\begin{array}{l}\text { The current study was to examine the temporal } \\
\text { relationship of physical exercise preceding } \\
\text { development of dementia. } \\
\text { Physical activity was assessed at baseline by an intervien } \\
\text { Cognitive function was assessed at baseline and follow } \\
\text { up using the CASI. } \\
\text { Follow-up: biennially for } 6.2 \text { years }\end{array}$ \\
\hline $\begin{array}{l}\text { Laurin et al }{ }^{12} \\
\text { Prospective study }\end{array}$ & $\begin{array}{l}\text { Physical activity and cognitive status were assessed } \\
\text { at baseline and follow-up. } \\
\text { Follow-up: } 5 \text { years }\end{array}$ \\
\hline
\end{tabular}

Lytle et al $^{13}$

Prospective study

Middleton et al ${ }^{14}$ Prospective study

Miu et al $^{9}$ RCT

Mortimer et al ${ }^{19}$ RCT
Physical activity was assessed at baseline through self-reporting and cognitive function was assessed at baseline and at follow-up using the MMSE. Follow-up: 2 years

Physical fitness was assessed at baseline and follow-up by using a battery of fitness and metabolism tests, and cognitive function was assessed at baseline and followup by using the $3 \mathrm{MS}$.

Follow-up: 2 or 5 years

Participants were randomized to a control group $(n=49)$ or a physical activity treatment group $(n=36)$. Physical fitness was assessed at baseline and follow-up by using a battery of physical function tests.

Cognitive status was assessed at baseline and follow-up using the MMSE and the ADAS-Cog.

Follow-up: 3,6 , 9, and 12 months

Participants were randomized into 4 groups: group I, Tai Chi $(n=30)$; group 2 , walking $(n=30)$; group 3 , social $(n=30)$; and group 4 , no intervention $(n=30)$ for a total of 40 weeks.

\section{Participants}

I, I 60 subjects

586 males and 574 females, $\geq 67$ years

Inclusion criteria: participants of the longitudinal Survey of Health and Living Status of the Elderly (Taiwan Department of Health) aged $\geq 67$ years.

Exclusion criteria: not stated

I,740 subjects

693 males and I,047 females, $\geq 65$ years

Participants of the ACT study

Inclusion criteria: ACT study participant with CASI score above

the 25th percentile; residing in the Seattle area at time of study.

Exclusion criteria: pre-existing dementia or cognitive impairment 4,6I5 subjects

I,83I males and 2,784 females, $\geq 65$ years

Participants of the 1991-1992 Canadian Study of Health and

Aging, a prospective cohort study of dementia.

Inclusion criteria: age $\geq 65$ years and registered in the 1991-1992

Canadian Study of Health and Aging.

Exclusion criteria: dementia

I, I46 participants

722 males versus 424 females, $\geq 65$ years

Participants of MoVIES

Inclusion criteria: Residing in the community of Monongahela

Valley (not in a skilled care facility) at time of recruitment; fluent

in English and having at least a 6th grade education.

Exclusion criteria: not described

197 subjects

Sex not stated

70-79 years

Participants of the Health $A B C$ study.

Inclusion criteria: ability to walk $0.4 \mathrm{~km}$, climb ten stairs, and perform basic activities of daily living without difficulty; no plans to leave the area for the next 3 years.

Exclusion criteria: life-threatening illness; mobility limitations;

cognitive impairment ( 3 MS score $<80$ )

85 participants

Sex not clearly stated

$\geq 65$ years

Participants of the memory clinic at a regional hospital in Hong Kong Inclusion criteria: mild-to-moderate dementia; MMSE 10-26; age

$>60$ years; community-dwelling; ambulatory, having a caregiver willing to participate and escort the patient to the hospital for training and assessment.

Exclusion criteria: severe dementia or MMSE score $<10$

120 subjects

40 males and 80 females

60-79 years

Inclusion criteria: participants of Jingansi Temple Community of Shanghai, China aged 60-79 years.

Exclusion criteria: history of stroke, Parkinson's disease, or other neurological disease; inability to walk unassisted for $2 \mathrm{~km}$ or maintain balance with feet side-by-side or semitandem for 10 seconds each; education-adjusted Chinese MMSE <26; cardiovascular disease; musculoskeletal conditions; contraindication for MRI; unable to participate in the full study and regular vigorous exercise or Tai Chi practice 
Interventions

\section{None}

Physical activity assessment: questionnaire survey at baseline.

Cognitive performance assessment: SPMSQ that was validated for the Chinese version of the MMSE

\section{None}

Physical exercise assessment: subject interview (number of days per week and number of hours per session) during the past year. Participants who exercised at least 3 times a week were classified as regular exercisers.

Cognitive status and incident dementia assessment: CASI

None

Physical fitness assessment: a self-administered questionnaire by mail.

Cognitive function assessment: $3 \mathrm{MS}$

None

Physical activity assessment: a standardized questionnaire.

Exercise was classified as aerobic (high level) or anaerobic (low level).

Cognitive status assessment: MMSE

None

Physical fitness assessment: doubly-labeled water techniques for total energy expenditure measurement between baseline and follow-up; a respiratory gas analyzer for measuring resting metabolic rate; an interviewer-administered questionnaire at first visit to ascertain physical activity habits over the past 7 days.

Cognitive status assessment: $3 \mathrm{MS}$ score

Treatment group: aerobic exercise training supervised by a physiotherapist, including treadmill, bicycle, and arm ergometry, and I0-minute flexibility training prior to each session. Training sessions occurred biweekly and lasted 45-60 minutes each. Total duration of treatment was 3 months.

Control group: no intervention

Tai Chi: practising 3 times per week (20 minutes warm-up, 30 minutes of Tai Chi practice, and 10 minutes cool-down).

Walking: a 400 m circular walking ( 10 minutes of warm-up, 30 minutes of brisk walking, and 10 minutes of cool-down exercise).

Social interaction: meeting with group leader for one hour 3 times per week.

Brain volume assessment: MRI at baseline and at the end of intervention (40 weeks).

Cognitive assessment: neuropsychological battery at baseline, 20 weeks, and 40 weeks
Cognitive function measurements

Ten-item SPMSQ

CASI (score $<86$ resulted in a neuropsychological clinical evaluation)

DSM-IV criteria for dementia (25 criteria in total)

3 MS score (a reduction of $\geq 5$ points indicative of cognitive decline)

MMSE score (drop of at least 3 points between assessments was indicative of cognitive decline)

$3 \mathrm{MS}$ score (a decline of at least one standard deviation or 9 points from baseline to the most recent follow-up visit indicated cognitive decline)

MMSE

ADAS-Cog

Brain volume using MRI

Neuropsychological battery test

(Continued) 
Table 2 (Continued)

\begin{tabular}{ll}
\hline $\begin{array}{l}\text { Source and } \\
\text { study design }\end{array}$ & Methods \\
\hline $\begin{array}{l}\text { Muscari et al }{ }^{20} \\
\text { RCT }\end{array}$ & $\begin{array}{l}\text { Subjects were randomized into a control group }(n=60) \\
\text { and a physical activity treatment group }(n=60) . \\
\text { Cognitive status was assessed at baseline and follow-up } \\
\text { by using the MMSE. } \\
\text { Follow-up: I } 2 \text { months }\end{array}$
\end{tabular}

Participants

120 subjects

62 males and 58 females

65-74 years

Inclusion criteria: participants of the Pianoro Study, aged 65-74

years.

Exclusion criteria: Presence of any cardiovascular disease and the followings; MMSE score $<24$; BMI $<18$ or $>32$; systolic BP $>$ I 80 or < II0 mmHg; diastolic BP < II0 mmHg; malignancy; moderate or severe respiratory insufficiency; severe arthrosis; recent fractures, palsy or relevant neuromotor deficits; hemoglobin < I I g/dL; aortic aneurysm $>3.5 \mathrm{~cm}$

Nagamatsu et al $^{26}$ RCT

Nguyen et $\mathrm{al}^{27}$ RCT

Podewils et $\mathrm{al}^{56}$ Prospective study

Ravaglia et $\mathrm{al}^{23}$ Prospective study

Scarmeas et $\mathrm{al}^{57}$ Prospective study

Schuit et $\mathrm{al}^{24}$ Prospective study
Subjects were randomized, single-blinded into: twice-weekly resistant training $(n=28)$; twice-weekly aerobic training $(n=30)$; or twice-weekly balance and tone training (control) group $(n=28)$.

Follow-up: 6 months

Participants were randomly divided into 2 groups; Tai Chi $(n=48)$ and control $(n=48)$ group. Experienced Tai Chi instructors were selected by investigators to teach classes. Outcome measures were assessed at baseline and the end of 6-month Tai Chi training. Follow-up: 6 months

Physical activity information was assessed at baseline and follow-up by interview and the 3MS, respectively. Follow-up: annually for 5.4 years

Physical activity was self-reported at baseline by using a questionnaire and cognitive status was measured at baseline and follow-up by using a neuropsychological test battery. Participants were screened for incident dementia using an extensive neuropsychological test battery.

Follow-up: 4 years

Physical activity was self-reported at baseline, and cases of incident dementia were identified at each follow-up using a neuropsychological test battery in conjunction a consensus diagnosis among an expert panel based on the DSM-IV criteria.

Follow-up: every I.5 years for 15 years

Physical activity was assessed at baseline through self reporting. Cognitive function was assessed at baseline and follow-up using the MMSE.

Follow-up: 3 years
86 subjects

All females

70-80 years

Inclusion criteria: female, aged $70-80$ years, with probable mild cognitive impairment.

Exclusion criteria: not described

102 subjects

48 males and 48 males

60-79 years

Inclusion criteria: MMSE score $>25$; having no experience in Tai Chi.

Exclusion criteria: serious diseases such as symptomatic coronary diseases, angina, arrhythmia, orthostatic hypotension, and dementia

3,375 subjects

I,350 males and 2,025 females

$\geq 65$ years

Inclusion criteria: enrollment in Cardiovascular Health

Cognition Study; residing in Sacramento County, CA,

Washington County, MD, Forsyth County, NC, or Pittsburgh,

PA, USA.

Exclusion criteria: dementia

749 subjects

348 males and 40 I females, $\geq 65$ years

Inclusion criteria: individuals $\geq 65$ years in the Conselice Study of Brain Ageing.

Exclusion criteria: per the Conselice Study of Brain Ageing

I,880 participants

587 males and I,293 females

70-82 years

Participants were recruited through the WHICAP from a sample of Medicare beneficiaries in northern Manhattan.

Inclusion criteria: WHICAP participants.

Exclusion criteria: not described

347 participants

All males

70-80 years

Inclusion criteria: participants of the Zutphen Elderly Study, the

Netherlands.

Exclusion criteria: per the Zutphen Elderly Study 
Interventions

Treatment group: 12 months of 3 one hour-long sessions per week of supervised endurance exercise training in a community group.

Control group: education to improve lifestyle and self-administered programs to increase physical activity

\section{Cognitive function measurements}

MMSE score (decrease of greater than one point was indicative of cognitive decline)
Resistant training group: a Keiser pressurized air system and free weights were used. Aerobic training group: an outdoor walking program.

Balance and tone training (control) group: stretching, range of motion, balance exercises, and relaxation technique

Treatment group: a 60-minute Tai Chi session twice a week for 6 months. The session consisted of a I5-minute warm-up and cool-down period.

Control group: no intervention, maintained daily routine activities and not to begin any new exercise program

None

Physical activity assessment: modified Minnesota Leisure Time Activity Questionnaire. Cognitive status assessment: 3MS or the Telephone Interview for Cognitive Status for participants who did not receive a clinical evaluation

None

Physical fitness assessment: Paffenbarger Physical Activity Questionnaire.

Cognitive status assessment: GDS, MMSE, and MDB for use in rural and poorly educated subjects

None

Physical activity assessment: two versions of the Godin leisure time exercise questionnaire.

Cognitive status assessment: a neuropsychological test battery testing the domains of memory, language, reasoning, processing speed, and visual-spatial ability

None

Physical fitness assessment: a self-administered questionnaire at baseline. Physical activity was categorized as either "maximal I hour/day" or "more than I hour/day".

Cognitive status assessment: MMSE at baseline and follow-up
Primary outcome measure:

Stroop Test performance

Secondary outcome measures: TMT,

Verbal Digits Test

Memorizing face-scene pairs

Everyday Problem Test

TMT for motor speed and visual attention

$3 \mathrm{MS}$ score ( $<80$ within the last 2 visits; decline of at least 5 points within the follow-up period;

Telephone Interview for Cognitive Status score of $<28$; diagnosis of dementia that was documented in medical records

MMSE (cognitive impairment defined as a score of $<24$ ) MDB

The decision of expert panel composed of neurologists and neuropsychologists in according to DSM-IV criteria

MMSE (drop in 3 points indicative of cognitive decline) 
Table 2 (Continued)

\begin{tabular}{|c|c|c|}
\hline $\begin{array}{l}\text { Source and } \\
\text { study design }\end{array}$ & Methods & Participants \\
\hline $\begin{array}{l}\text { Smiley-Oyen et } \mathrm{al}^{2 \mathrm{I}} \\
\mathrm{RCT}\end{array}$ & $\begin{array}{l}\text { Participants were randomized to an aerobic physical } \\
\text { activity (Cardio, } n=28 \text { ) group or a strength- } \\
\text { and-flexibility (Flex-Tone, } n=29 \text { ) training group. } \\
\text { Physical fitness was assessed at baseline and follow-up } \\
\text { using a battery of fitness tests, and cognitive status } \\
\text { was assessed at baseline and follow-up by using a } \\
\text { battery of neurocognitive tests. } \\
\text { Follow-up: at } 4 \text { and } 10 \text { months }\end{array}$ & $\begin{array}{l}62 \text { subjects } \\
16 \text { males and } 4 \text { I females } \\
65-79 \text { years } \\
\text { Residents of the mid-western US } \\
\text { Inclusion criteria: living independently; able to exercise safely. } \\
\text { Exclusion criteria: various health-related reasons (autoimmune } \\
\text { disease, cancer diagnosis within the previous } 5 \text { years, or } \\
\text { conditions which may be exacerbated by strenuous exercise); } \\
\text { being "too-fit" ( participation in exercise }>3 \text { times/week at } \\
>40 \% \text { of their heart rate reserve), or participant's aerobic fitness } \\
\text { level above the 75th percentile for their age and sex by a time } \\
\text { walking test) }\end{array}$ \\
\hline Taaffe et $a^{58}$ & Physical activity was assessed at baseline by & 2,263 subjects \\
\hline Prospective study & $\begin{array}{l}\text { self-reporting and performance. } \\
\text { The incident dementia was assessed at baseline } \\
\text { and follow-up using CASI. } \\
\text { Follow-up: at } 3 \text { and } 6 \text { years }\end{array}$ & $\begin{array}{l}\text { All males } \\
71-92 \text { years } \\
\text { Inclusion criteria: enrollment in the Honolulu-Asia Aging Study; } \\
\text { Japanese-American men born between } 1900 \text { and } 1919 \text { living on } \\
\text { the island of Oahu, Hawaii. } \\
\text { Exclusion criteria: dementia }\end{array}$ \\
\hline
\end{tabular}

Van Gelder et al $^{59} \quad$ Physical activity was assessed at baseline and at followProspective study

Wang et al $^{60}$ Prospective study

Wang et al ${ }^{15}$ Prospective study

Williamson et $\mathrm{al}^{8}$ RCT up by using a self-administered questionnaire, and cognitive status was assessed at baseline and at followup by using MMSE.

Follow-up: at 5 and 10 years

Physical fitness was assessed at baseline by using a physical function test battery and cognitive function was assessed at baseline and follow-up by using a neurocognitive test battery. Follow-up: biennially through October 2003 (8-10 years)

Leisure activity levels and cognitive status assessment were performed at baseline and follow-up. Follow-up: mean $2.4(2.3-2.6)$ years
Subjects were randomized to a control group $(n=52)$ or a physical activity treatment group $(n=50)$. Physical fitness was assessed at baseline and followup using a battery of performance tests for balance, walking speed, and sitting-to-standing time.

Cognitive function was assessed at baseline and follow-up by using a neuropsychological test battery. Follow-up: 12 months
295 subjects

All males

70-90 years

Inclusion criteria: participants of the Surviving cohorts of the Seven Countries Study in Europe.

Exclusion criteria: poor health (myocardial infarction, stroke, diabetes, or cancer); severe cognitive impairment (MMSE <18) 2,228 subjects

863 males versus I,365 females

$\geq 65$ years

Inclusion criteria: participants of the Adult Changes in Thought study (1994-1996) Exclusion criteria: CASI <86; dementia; invalid measurements on the cognitive performance test or physical performance test at baseline; persons without a followup examination

I,463 subjects

744 males and 719 females

$\geq 65$ years

Participants of a longitudinal population-based study of aging in the People's Republic of China between 2003 and 2005.

Inclusion criteria: residents aged $\geq 65$ years in the study regions. Exclusion criteria: baseline global cognitive score in the bottom $10 \%$; physical disability

102 participants

50 males and 72 females

70-89 years

Participants of the LIFE-P study

Inclusion criteria: sedentary lifestyle; ability to walk 400 m in 15 minutes without resting or assistance; SPPB score $\leq 9$.

Exclusion criteria: MMSE $<2$ I; life expectancy of $<12$ months;

heart disease; severe neurological conditions such as Parkinson's disease during time of study 


\section{Interventions}

Cardio group: a 10-month of tri-weekly training sessions (10-minute warm-up, 25-30 minutes of aerobic exercise on the equipment of the participant's choice (treadmill, stair-stepping machine, stationary cycle, and elliptical machine), and a 10-minute cool down.

Flex-Tone group: A 10-month tri-weekly training sessions (10-minute warm-up, 25-30 minutes of strength, flexibility, and balance exercises (yoga, Tai Chi, Flex bands, free hand weights, resistance weight training machines, and stability balls), and a 10 -minute cool down; 8-10 exercises of $1-15$ repetitions each were performed

\section{None}

Physical activity assessment: a self-reported questioner.

Physical function assessment: four performance tasks, ie, timed walk, sitting-to-standing time, grip strength, and balance.

Cognitive status assessment: CASI used as the initial assessment. For CASI $<74$, subjects underwent a second phase of screening (a repeat CASI and administration of the IQCODE). Men with an IQCODE score of $>3.6$ underwent a third phase assessment (a standardized interview and neuropsychological battery, neurological examination, neuroimaging, and blood testing)

None

Physical fitness assessment: a self-administered questionnaire.

Physical activity was categorized into four groups: $<30,31-60,61-120$, and

$>120$ minutes per day.

Cognitive status assessment: MMSE

\section{None}

Physical fitness assessment: Four different physical performance tests (timed walk, seating-to-standing time, standing balance, grip strength).

Cognitive function assessment: CASI

\section{None}

Leisure activities assessment: a self-reported questionnaire in predefined list of mental, physical and social activities.

Cognitive assessment: face-to-face interviews at the home of subjects using the followings; CSID, Word List Learning, Word List Recall, IU Story Recall, Animal Fluency Test, IU Token Test

Treatment group: physical activity intervention consisting of a combination of aerobic, strength, balance, and flexibility exercises divided into 3 phases: adoption (weeks I-8), transition (weeks 9-24), and maintenance (week 25 to end of study).

Control group: health education intervention designed to provide attention and health education to participants. Participants met in small groups weekly for the first 26 weeks and then monthly to the end of the study

\section{Cognitive function measurements}

Reaction time tests including simple reaction time, 8-choice reaction time, 8-choice incompatible reaction time, and Go/No-Go reaction time

Stroop Color and Word Test

Wisconsin Card Sort Test

CASI (scores $<74$ indicative of possible dementia) IQCODE (scores $<3.6$ indicative of probable dementia) Diagnoses were finally decided by consensus of an appointed expert panel

MMSE (scores $<18$ indicative of cognitive decline)

CASI (score $\geq 86$ were categorized as dementia-free)

Global cognitive function: CSID

Episodic memory: Word List Learning, Word List Recall, IU Story Recall

Language: Animal Fluency Test

Executive function: IU Token Test

Digit Symbol

Substitution Test

Modified Stroop Test

MMSE

The Rey Auditory Verbal Learning Test 
Table 2 (Continued)

\begin{tabular}{|c|c|c|}
\hline $\begin{array}{l}\text { Source and } \\
\text { study design }\end{array}$ & Methods & Participants \\
\hline Yaffe et al ${ }^{16}$ & Physical activity was self-reported at baseline through & 5,925 subjects \\
\hline \multirow[t]{9}{*}{ Prospective study } & both interview and questionnaire. Cognitive function & All females \\
\hline & was assessed at baseline and follow-up using the $3 \mathrm{MS}$. & $\geq 65$ years \\
\hline & Follow-up: $6-8$ years & Inclusion criteria: participants of the Study of Osteoporotic \\
\hline & & Fractures (a prospective study for risk factors of fractures in \\
\hline & & Baltimore, MD, Minneapolis, MN, Pittsburgh, PA, or Portland, \\
\hline & & OR, USA). \\
\hline & & Exclusion criteria: black women; unable to walk without \\
\hline & & assistance; bilateral hip replacements; baseline cognitive \\
\hline & & impairment; baseline physical limitations \\
\hline
\end{tabular}

Abbreviations: 3MS, Modified Mini-Mental State; ACT, Adult Changes in Thought; ADAS-Cog, Alzheimer's Disease Assessment Scale-Cognitive subscale; BMI, body mass index; BP, blood pressure; CASI, Cognitive Abilities Screening Instrument; CSID, Community Screening for Dementia; DSM-IV, Diagnostic and Statistical Manual of Mental Disorders, Fourth Edition; Health ABC, Health, Aging, and Body Composition; GDS, Geriatric Depression Scale; YPAS, Yale Physical Activity Survey; LIFE-P, Lifestyle Interventions and Independence for Elders Pilot; MDB, Mental Deterioration Battery; MMSE, Mini-Mental State Examination; RBMT, Rivermead Behavioural Memory Test; FCSRT, Free and Cued Selective Reminding Test; MRI, magnetic resonance imaging; TMT, Trail Making Tests; SPMSQ, Short Portable Mental Status Questionnaires; 3GM, Modified Mini-Mental Status Examination; MoVIES, Monongahela Valley Independent Elders Survey; SPPB, Short Physical Performance Battery; RCT, randomized controlled trial; WHICAP, Washington Heights-Inwood Columbia Aging Project; IQCODE, Informant Questionnaire on Cognitive Decline in the Elderly; AD, Alzheimer's disease; RM, repetition maximum; IU, Indiana University.

\section{Effect of physical activity intervention}

Twenty-seven studies (Table 1) met the inclusion criteria for this review. Of these, 26 studies reported a significant association between physical activity and cognitive function in late life (Tables 3 and 4). Of the ten RCTs, nine showed a positive correlation and one showed a nonsignificant correlation. ${ }^{9}$ Although these studies included both male and female subjects, one RCT by Klusmann et al ${ }^{10}$ enrolled only elderly healthy female subjects. As compared with controls, the authors also found a significant benefit of physical exercise (aerobic training with a bicycle ergometer or treadmill) in this elderly female population. Therefore, the majority of the studies concluded that physical activity in later life confers a protective effect on cognition in elderly subjects. Additionally, there were five studies ${ }^{11-16}$ that reported a dose-response association between physical activity and cognitive function.

\section{Discussion}

This review examined the effect of physical activity in late life on age-related cognitive decline in older individuals with normal cognitive function or mild cognitive impairment at baseline. When selecting studies for review, the assumption was made that there is no difference in effect on cognition between different physical activities, ranging from aerobic to isometric exercises. As such, all types of physical activity program interventions were accepted in the study selection process. The data indicate that this assumption was generally correct; 26 of 27 studies showed a significant association between physical activity and cognitive decline, whereby an increased level of physical activity resulted in attenuation of cognitive decline and cognitive disease (Tables 3 and 4). In the ten RCTs evaluated in this review, the different interventions included aerobic and isometric exercise, weight training, and Tai Chi. Eight of these studies showed a significant outcome benefit, with one study showing a nonsignificant correlation (Table 4). Although these trials were not designed to determine a threshold effect or doseresponse effect, there were five prospective studies suggesting a dose-response relationship in the level of benefit found with exercise, ${ }^{11-16}$ thus providing additional credence to the specificity of the effects of exercise on cognitive function.

\section{Implications of evidence quality}

Despite the preponderance of positive studies, only nine of the 27 studies were considered to be of high quality and the overall risk of bias was moderate in 16 studies (Table 1). Many studies included in this review relied on self-reporting to assess exercise habits, rather than using a more objective means of measuring physical activity.

In the studies evaluated in this review, outcome measures of cognitive performance were wide-ranging and measured different aspects of cognitive function (Table S3). Several studies used a neuropsychological test battery to test multiple aspects of cognitive function, while other studies used only one or two cognitive tests. Data heterogeneity may have confounded identification of the domains of cognitive function that were most affected by exercise. We standardized the cognitive metrics, inclusion criteria, and outcomes in this review as much as possible, which may have enabled us to ascertain an association between exercise and a few specific domains of cognitive function, such as the MMSE and Cognitive Inhibition (Stroop Color and Word Test). In the nine studies considered to be of higher quality, seven were $\mathrm{RCTs}^{9,10,17-21}$ 
None

Physical fitness assessment: a self-reported questionnaire and a modified Paffenbarger scale (to quantify frequency and duration of weekly participation in 33 different physical activities) administered by trained interviewees.

Cognitive function assessment: $3 \mathrm{MS}$
3MS score (cognitive decline defined as a decrease in 3

or more points from baseline to follow-up) and two were prospective studies. ${ }^{14,22}$ In these studies, a positive correlation was evident between physical activity in later life and cognition in the elderly subjects evaluated.

Similarly, the types of physical activity interventions used in the studies reviewed were wide-ranging, from aerobic or isometric physical activity, or combinations of both. Given the variability in physical activity interventions and the measures of cognitive function, it was not possible to determine a distinct relationship between specific types of physical activity and improvements in specific cognitive domains. As such, better standardization of the types of physical activity interventions could have clarified the specific causal relationships more effectively.

The durations of the included studies ranged from 6 months to several years. It is possible that improvements in some aspects of cognitive function occur shortly after completion of an exercise program, while improvements in other aspects may take several months or years to develop. For example, when using the $3 \mathrm{MS}$ or MMSE as one of the outcome measures, there was only one study showing a positive effect at 12 months ${ }^{20}$ whereas the other two did not; 8,9 and five studies demonstrated the positive impact of exercise on cognitive function over the course of more than 12 months. ${ }^{12,16,23-25}$ The positive effect of exercise on cognitive speed ${ }^{26,27}$ and cognitive inhibitory function $^{21}$ can be observed as early as 6 months. These observations highlight the time-specific effect of physical activity on each cognitive domain. Of interest, a study by Segal et $\mathrm{a}^{28}$ found that the acute effects of exercise enhance learning ability in patients with mild cognitive impairment and subjects with normal cognition. These investigators postulated that exercise could function as a stimulus for memory consolidation due to its stimulatory effects on the locus coeruleus and consequent release of norepinephrine. They found that exercise, conducted acutely after a period of learning, significantly increased the release of endogenous norepinephrine in both types of study subjects and resulted in retrograde enhancement of memory. ${ }^{28}$ As such, acute exercise, associated with periods of learning, may be a positive therapeutic intervention for cognitive decline in elderly subjects. In future research, it would be important to determine which forms of exercise affect specific domains of cognition and, also, the latency and duration of effect.

An exclusion criterion for this review was the presence of specific underlying conditions or diseases in the study population (such as chronic obstructive pulmonary disease, diabetes, traumatic head injury, cardiovascular disease, or depression). Therefore, our findings cannot be extrapolated to individuals with chronic underlying conditions in whom improvements in cognitive performance following a program of physical activity may be diminished or not apparent. For example, Hoffman et $\mathrm{al}^{29}$ published an RCT in which a program of physical activity failed to improve neurocognition in elderly subjects with clinical depression. This also has implications when assessing the overall effectiveness of physical activity in later life on cognitive performance in the very elderly, since a significant proportion of this population suffers from chronic conditions that may impede improvements in cognitive function following a physical activity regimen.

\section{Neural plasticity: possible mechanisms for effect of exercise on cognition}

Decline in cognitive function is one of the hallmarks of the aging process. The concept of neuronal structural plasticity 
Table 3 Results of included studies

Source and study Results
design

Buchman et a ${ }^{22}$

Prospective study

Busse et al ${ }^{17}$

RCT

Bixby et al ${ }^{62}$

Observational

Cassilhas et al ${ }^{18}$

RCT

Geda et $\mathbf{a}^{|6|}$

Case control

Klusmann et al ${ }^{10}$

RCT

Ku et al"

Prospective study

Larson et al ${ }^{55}$

Prospective study

Laurin et al ${ }^{12}$

Prospective study

Lytle et al ${ }^{13}$

Prospective study

Middleton et al ${ }^{14}$

Prospective study

Miu et al ${ }^{9}$

RCT

Mortimer et al ${ }^{19}$

RCT

Muscari et $\mathrm{al}^{20}$

RCT

Nagamatsu et al $^{26}$

RCT

Nguyen et $\mathrm{al}^{27}$

RCT

Podewils et a ${ }^{56}$ Prospective study
Total daily physical activities were associated with incident Alzheimer's disease (hazard ratio $0.477,95 \%$ confidence interval 0.273-0.832).

After 9 months, the physical activity group showed a significant increase in RBMT score from pre-test to post-test, while the control group showed no increase.

A small but significant association between physical fitness and executive function in the sample of older men and women.

Both moderate-intensity and high-intensity resistance exercise programs had equally beneficial effects on cognitive functioning. However, the study was not able to identify a dose-response relationship between level of exercise and level of cognitive functioning.

The odds ratio for any frequency of exercise of at least a moderate level in late life was 0.68 , suggesting that any frequency of moderate-intensity exercise performed in late life is associated with a reduced odds ratio of mild cognitive impairment. Both the exercise group (mean \pm SD change $2.09 \pm 2.66, P<0.00 \mathrm{I}$ ) and the computer group (mean \pm SD change $1.89 \pm 2.88$, $P<0.00 \mathrm{I}$ ) showed improved delayed story recall. They maintained performance in delayed word recall and working memory (time measure) as opposed to the control group that showed a decline (mean \pm SD change $-0.91 \pm 2.15, P=0.00 \mathrm{I}$, and mean $\pm S D$ change $0.24 \pm 0.68, P=0.04$, respectively). In conclusion, in older healthy women, exercise and computer classes seem to generate equivalent beneficial effects.

Using the multivariate adjustment (controlling for sociodemographic variables, lifestyle behavior, and health status), higher initial levels of physical activity were significantly associated with better initial cognitive performance (standardized coefficient $\beta=0.17)$. A higher level of physical activity at baseline was significantly related to slower decline in cognitive performance, as compared with a lower level of activity $(\beta=0.22)$. The authors conclude that physical activity in later life is associated with slower age-related cognitive decline.

During the follow-up period, 158 participants developed dementia while 107 developed Alzheimer's disease. The interaction between exercise and incident dementia or Alzheimer disease was found to be statistically significant. The incidence rate of dementia was 13.0 per I,000 person-years for participants who exercised 3 or more times per week, compared with 19.7 per I,000 person-years for those who exercised less than 3 times per week. Similar results were observed in analyses for incident Alzheimer's disease.

The results showed that, compared with no exercise, physical activity was significantly associated with lower risks of cognitive impairment of all types, including dementia and Alzheimer's disease. Furthermore, a significant dose-response relationship was observed whereby greater physical activity was associated with increased protection for cognitive decline and disease. A significant negative association (positive effect of exercise) between both low and high exercise and cognitive decline was observed.

The results showed that older adults in the highest level of activity energy expenditure had lower odds of incident cognitive impairment than those in the lowest levels of activity energy expenditure. Furthermore, a significant doseresponse relationship was observed between incident activity energy expenditure and incidence of cognitive impairment. Eighty-two patients were available for analysis. The results showed no statistically significant difference between the treatment or control groups in terms of cognitive function.

One hundred and twenty subjects were analyzed. In comparison with a no intervention group, Tai Chi and social intervention showed an increase of brain volume via magnetic resonance imaging $(P<0.05)$ and improvement in several neuropsychological measures $(P<0.05)$. No difference was observed between the walking and the no intervention group. This result differs from the previous trials in that the increase of brain volume and cognitive function in the current study is associated with nonaerobic exercise and social interaction.

One hundred and nine patients were available for analysis. A significant decrease in MMSE score in the control group was observed, and the odds ratio for treated older adults having stable cognitive status one year later (as compared with the control group) was 2.74 , suggesting that a 12 -month endurance exercise training program may delay the onset of agerelated cognitive decline in the elderly.

Resistance training participants had significantly improved performance on the Stroop Test, an executive cognitive test of selective attention/conflict resolution and the associated memory task compared with subjects in a balance and tone training group ( $P=0.04$ and $P=0.03$, respectively). This study suggests that twice-weekly resistance training could alter the trajectory of cognitive decline in seniors with mild cognitive impairment.

There were no significant differences between balance, sleep quality, and cognitive performance test. At the end of the study, participants in the Tai Chi training group showed a significantly $(P<0.00 \mathrm{I})$ higher Trail Making Test score in part $\mathrm{A}$ (44.2 \pm 4.5 versus $35 \pm 4.3)$ and part $B(118.3 \pm 6.4$ versus $102 \pm 5)$.

Participants in the highest quartile of physical energy expenditure had a relative risk of dementia of 0.85 compared with those in the lowest quartile, and participants who participated in more than four physical activities had a relative risk of dementia of $0.5 \mathrm{I}$ as compared with those who participated in 0 or I physical activities. Similar results were observed with risk of Alzheimer's disease.

(Continued) 
Table 3 (Continued)

\begin{tabular}{|c|c|}
\hline $\begin{array}{l}\text { Source and study } \\
\text { design }\end{array}$ & Results \\
\hline $\begin{array}{l}\text { Ravaglia et } \mathrm{a}^{23} \\
\text { Prospective study }\end{array}$ & Physical activity is associated with a lowered risk of vascular dementia, but not of Alzheimer's disease. \\
\hline $\begin{array}{l}\text { Scarmeas et al }{ }^{57} \\
\text { Prospective study }\end{array}$ & $\begin{array}{l}\text { During a mean of } 5.4 \text { years of follow-up, a total of } 282 \text { incident Alzheimer's disease cases occurred. The hazard ratio for } \\
\text { some physical activity (compared with no physical activity) was } 0.67 \text {, and for much physical activity was } 0.67 \text {. This study } \\
\text { suggests that physical activity is associated with a reduced risk for Alzheimer's disease. }\end{array}$ \\
\hline $\begin{array}{l}\text { Schuit et al }{ }^{24} \\
\text { Prospective study }\end{array}$ & $\begin{array}{l}\text { Subjects with one hour or less of daily physical activity were at doubly increased risk of cognitive decline as compared } \\
\text { with subjects who participated in more than one hour of physical activity daily. This study suggests that promotion of } \\
\text { physical activity at an advance aged may reduce the risk of cognitive decline. }\end{array}$ \\
\hline $\begin{array}{l}\text { Smiley-Oyen et } \mathrm{al}^{21} \\
\text { RCT } \\
\text { Taaffe et al }{ }^{58} \\
\text { Prospective study }\end{array}$ & $\begin{array}{l}\text { The results showed improvements in performance on the Stroop Color and Word Test only in the aerobic exercise } \\
\text { group, and the study failed to show a dose-response relationship. } \\
\text { For men with low physical function at baseline, high levels of exercise were associated with half the dementia risk as } \\
\text { compared with men who were the least active. A moderate level of physical activity was found to be protective, because } \\
\text { the risk of dementia and Alzheimer's disease decreased significantly with higher levels of physical activity. However, the } \\
\text { study was not able to identify a correlation between dementia and Alzheimer's disease risk and physical activity in men } \\
\text { with moderate or high levels of physical activity at baseline. }\end{array}$ \\
\hline $\begin{array}{l}\text { Van Gelder et } \mathrm{a}^{59} \\
\text { Prospective study }\end{array}$ & $\begin{array}{l}\text { While there was no difference in the rates of cognitive decline between men with a high or low duration of physical } \\
\text { activity at baseline, it was observed that a decrease in physical activity duration }>60 \text { minutes per day over } 10 \text { years } \\
\text { resulted in a decline of I.7 points in the MMSE. Further, men in the lowest physical activity intensity quartile had a 10-year } \\
\text { cognitive decline I.8 times greater than that observed in men in the higher physical activity intensity quartiles. This study } \\
\text { suggests that participation in physical activities of at least low-medium intensity in old age may delay the onset of cognitive } \\
\text { decline. }\end{array}$ \\
\hline $\begin{array}{l}\text { Wang et al }{ }^{60} \\
\text { Prospective study }\end{array}$ & $\begin{array}{l}\text { During the I0-year period, } 319 \text { participants developed dementia and } 221 \text { developed Alzheimer's disease. The results } \\
\text { showed that a one-point decrease in performance-based physical function test scores was associated with an increased } \\
\text { risk of dementia and Alzheimer's disease. This study suggests that poor physical function may lead to onset of dementia } \\
\text { and Alzheimer's disease, while higher levels of physical fitness may delay onset of cognitive decline and disease. }\end{array}$ \\
\hline $\begin{array}{l}\text { Wang et al }{ }^{15} \\
\text { Prospective study } \\
\text { Williamson et al } \\
\text { RCT }\end{array}$ & $\begin{array}{l}\text { A high level of physical activity was related to less decline in episodic memory }(P<0.05) \text { and language }(P<0.01) \text {. When } \\
\text { mental, physical, and social activities were integrated into a composite activity index, a dose-response pattern was observed. } \\
\text { Ninety participants were available for analysis at the end of the study. The results did not show a significant difference } \\
\text { between the groups; however, improvements in cognitive test scores on the Digit Symbol Substitution Test, Rey Auditory } \\
\text { and Verbal Learning Test, and modified Stroop Test were associated with improvements in physical function. }\end{array}$ \\
\hline $\begin{array}{l}\text { Yaffe et al }{ }^{16} \\
\text { Prospective study }\end{array}$ & $\begin{array}{l}\text { Women with a greater baseline physical fitness level were less likely to undergo cognitive decline during the } 6-8 \text {-year } \\
\text { follow-up period. A dose-response relationship was observed whereby cognitive decline occurred in } 17 \%, 18 \%, 22 \% \text {, and } \\
24 \% \text { of women in the highest, third, second, and lowest quartiles of physical activity as measured by blocks walked per } \\
\text { week. Similar results were obtained when analyzing quartiles of kilocalorie expenditure. This study suggests that women } \\
\text { with higher levels of baseline physical activity and fitness are less likely to develop cognitive decline. }\end{array}$ \\
\hline
\end{tabular}

Abbreviations: RBMT, Rivermead Behavioural Memory Test; RCT, randomized controlled trial; MMSE, Mini-Mental State Examination.

in learning and memory processes ${ }^{30,31}$ suggests that cognitive decline in aging may be associated with dysregulation of brain plasticity. ${ }^{32}$ Mahncke et $\mathrm{al}^{33}$ demonstrated that elderly subjects with normal cognitive function had enhancement of memory following an intensive, plasticity-based computer training program. Physical exercise ${ }^{34,35}$ promotes positive neuroplasticity, increases cognitive reserve and higher neuronal connection

Table 4 Association between physical activity and cognitive function in selected studies

\begin{tabular}{lll}
\hline Level of association & Number of studies & References \\
\hline Significant & 26 & $8,10-24,26,27,55-62$ \\
Insignificant & 1 & 9 \\
No association & 0 & N/A \\
Total & 27 & (See above references) \\
\hline
\end{tabular}

Abbreviation: N/A, not applicable. density, and results in improved cognitive function. On the contrary, negative neuroplasticity results from physical inactivity, poor nutrition, substance abuse, and social isolation, decreases cognitive reserve, and inhibits formation of neuronal connections, leading to reduced cognitive function. . $^{1,36,37}$

\section{Cerebral blood flow}

While both aerobic and isometric physical activity are thought to confer improved cognition, studies suggest that aerobic exercise may be more effective in slowing degenerative neurological processes that lead to age-related cognitive decline and dementia. ${ }^{38}$ How might aerobic exercise contribute to neuroprotection? Many processes leading to cognitive decline stem from atherosclerotic or cerebrovascular conditions that produce cerebral hypoperfusion. ${ }^{39}$ Ruitenberg et al 
found that higher cerebral blood flow velocity was significantly associated with less cognitive decline and lower velocity was related to Alzheimer's disease. ${ }^{40}$ The capacity of long-term aerobic exercise to mitigate the effects of vascular disease is well established, ${ }^{41}$ and may be an important mechanism of cognitive preservation due to exercise. Other mechanisms of neuronal enhancement with exercise include the role of neurotransmitters, changes in brain vasculature, and effects of neurotrophins. ${ }^{42,43}$ These processes, individually or together, may attenuate neurodegeneration and confer neuroprotective benefits, resulting in improved cognitive function.

\section{Angiogenesis}

Angiogenesis, the formation of vasculature by pre-existing endothelial cells, occurs in the brain during development but declines with age. Animal models have shown that exercise induces angiogenesis of small-vessel vasculature in the cerebellum, motor cortex, and hippocampus. Animal studies have shown that the hippocampus, which is essential for memory formation, is highly oxygen-dependent. Consequently, hippocampal angiogenesis may explain improvements in learning and memory following sustained, moderate-level physical activity. Maximal oxygen consumption increases with aerobic exercise, which is thought to be effective in promoting brain angiogenesis in experimental animals (rodents ${ }^{43}$ and monkeys ${ }^{42}$ ). Therefore, aerobic exercise may have more impact on cognitive performance than isometric exercise.

\section{Effects of cytokines, neurotrophins, and brain volume}

Neurotrophins are endogenous brain proteins that serve to promote neuroplasticity, and are thought to play a central role in response to physical activity. ${ }^{44}$ Granulocyte colonystimulating factor (G-CSF) and brain-derived neurotrophic factor (BDNF) are implicated in mediating increases in cerebral gray matter volume and hippocampal volume, respectively, ${ }^{45}$ and enhancing cognitive performance by optimizing cognitive reserve, increasing learning capacity, and streamlining memory processes. ${ }^{45}$ The effect of G-CSF in subjects undergoing exercise protocols has been evaluated in several studies; plasma levels of G-CSF have been found to increase significantly after short bursts of aerobic exercise ${ }^{46}$ as well as following periods of endurance exercise. ${ }^{47}$ The role of G-CSF on neutrophil activation, proliferation, and survival is important for the immune response, thus illustrating the possible correlation with exercise in immunomodulation. BDNF is integral to differentiation, extension, and survival of neurons in the hippocampus, cortex, and cerebellum during brain development, ${ }^{48-50}$ and increases levels of synaptophysin and synaptobrevin, substances that aid transport of neurotransmitter vesicles. Support for this mechanism comes from animal studies showing that regulation of BDNF is associated with physical activity, as demonstrated by increased BDNF gene expression in rats as a result of running, ${ }^{25,51}$ with diminished or nonapparent effects when BDNF production is blocked. ${ }^{52}$ The role of BDNF in cognitive impairment remains inconclusive, with studies reporting different results. ${ }^{53,54}$ Nevertheless, the importance of BDNF in preservation and enhancement of cognitive function in humans was demonstrated by Erickson et al, ${ }^{45}$ who found that decreased levels were associated with age-related decline in hippocampal volume, and that aerobic exercise increased BDNF, hippocampal and temporal lobe volumes, and spatial memory. The association between BDNF level, hippocampal volume, and dementia was also established at the molecular level in subjects with BDNF gene polymorphism. ${ }^{52}$

\section{Conclusion}

There is evidence suggesting that physical activity in later life is beneficial for cognitive function in elderly persons. These benefits include enhancement of existing cognitive function and maintenance of optimal cognitive function, as well as prevention or delayed progression of cognitive diseases, such as Alzheimer's dementia or other neurocognitive disorders. However, the majority of the evidence included in this review was of medium quality, and the overall risk of bias in the studies used in this review is moderately high. Despite the variable quality of the evidence, most of the data supports the concept that moderate-level physical activity in late life may improve cognitive function and delay the onset of debilitating cognitive disease in older persons. More evidence obtained from larger RCTs, preferably lasting for at least one year, is needed to confirm the association between physical activity in late life and improvements in cognitive function. Future research should focus on whether aerobic or isometric physical activity has a greater effect on cognition in the elderly, and which cognitive domains are most affected by physical activity. Additionally, research should be directed toward identifying and implementing exercise programs that would produce extended results on cognitive function in elderly patients.

\section{Acknowledgment}

The authors acknowledge the Department of Veterans Affairs, Queen's University Belfast and The John Butler Lung Foundation for their support of this work. 


\section{Disclosure}

The authors report no conflicts of interest in this work.

\section{References}

1. Vance D, Wright M. Positive and negative neuroplasticity: implications for age-relative cognitive declines. J Gerontol Nurs. 2009;35:11-17.

2. Kinsella K, He W. An Aging World: 2008. US Census Bureau, International Population Reports. Available from: http://www.census. gov/prod/2009pubs/p95-09-1.pdf. Accessed January 6, 2009.

3. Wimo A, Winblad B, Johnsson L. The worldwide societal costs of dementia: estimates for 2009. Alzheimers Dement. 2010;6:98-103.

4. Plassman BL, Williams J, Burke JR, Holsinger T, Benjamin S. Systematic review: factors associated with risk for and possible prevention of cognitive decline in later life. Ann Intern Med. 2010;153:182-193.

5. Maaike A, Geert A, Verhaar H, Aleman A, Luc V. Physical activity and enhanced fitness to improve cognitive function in older people without known cognitive impairment. Cochrane Database Syst Rev. 2008;2:1-37.

6. Forbes D, Forbes S, Morgan DG, Markle-Reid M, Wood J, Culum I. Physical activity programs for persons with dementia. Cochrane Database Syst Rev. 2008;3:1-26.

7. Tseng CN, Gau BS, Lou MF. The effectiveness of exercise on improving cognitive function in older people: a systematic review. J Nurs Res. 2011;19:119-131.

8. Williamson JD, Espeland M, Kritchevsky SB, et al. Changes in cognitive function in a randomized trial of physical activity: results of the lifestyle interventions and independence for elders pilot study. J Gerontol A Biol Sci Med Sci. 2009;64A:688-694.

9. Miu DKY, Szeto SL, Mak YF. A randomized controlled trial on the effect of exercise on physical, cognitive, and affective function in dementia subjects. Asian J Gerontol Geriatr. 2008;3:8-16.

10. Klusmann V, Evers A, Schwarzer R, et al. Complex mental and physical activity in older women and cognitive performance: a 6-month randomized controlled trial. J Gerontol A Biol Sci Med Sci. 2010;65A: 680-688.

11. Ku PW, Stevinson C, Chen LJ. Prospective associations between leisuretime physical activity and cognitive performance among older adults across an 11-year period. J Epidemiol. 2012;22:230-237.

12. Laurin D, Verreault R, Lindsay J, MacPherson K, Rockwood K. Physical activity and risk of cognitive impairment and dementia in elderly persons. Arch Neurol. 2001;58:498-504.

13. Lytle ME, Vander Bilt J, Pandav RS, Dodge HH, Ganguli M. Exercise level and cognitive decline: the MoVIES project. Alzheimer Dis Assoc Disord. 2012;18:57-64.

14. Middleton LE, Manini TM, Simonsick EM, et al. Activity energy expenditure and incident cognitive impairment in older adults. Arch Intern Med. 2011;171:1251-1257.

15. Wang HX, Jin Y, Hendrie HC, et al. Late life leisure activities and risk of cognitive decline. J Gerontol A Biol Sci Med Sci. 2012;68:205-213

16. Yaffe K. A prospective study of physical activity and cognitive decline in elderly women: women who walk. Arch Intern Med. 2001;161: 1703-1708.

17. Busse AL, Filho W, Magaldi R, et al. Effects of resistance training exercise on cognitive performance in elderly individuals with memory impairment: results of a controlled trial. Einstein. 2008;6:402-407.

18. Cassilhas R, Viana V, Grassmann V, et al. The impact of resistance exercise on the cognitive function of the elderly. Med Sci Sports Exerc. 2007;39:1401-1407.

19. Mortimer JA, Ding D, Borenstein AR, et al. Changes in brain volume and cognition in a randomized trial of exercise and social interaction in a community-based sample of non-demented Chinese elders. J Alzheimers Dis. 2012;30:757-766.
20. Muscari A, Giannoni C, Pierpaoli L, et al. Chronic endurance exercise training prevents aging-related cognitive decline in healthy older adults: a randomized controlled trial. Int J Geriatr Psychiatry. 2010;25: 1055-1064.

21. Smiley-Oyen A, Lowry K, Francois S, Kohut M, Ekkekakis P. Exercise, fitness, and neurocognitive function in older adults: the selective improvement and cardiovascular fitness hypotheses. Ann Behav Med. 2008;36:280-291.

22. Buchman AS, Boyle PA, Yu L, Shah RC, Wilson RS, Bennett DA. Total daily physical activity and the risk of $\mathrm{AD}$ and cognitive decline in older adults. Neurology. 2012;78:1323-1329.

23. Ravaglia G, Forti P, Lucicesare APN, Rietti E, Bianchin M, Dalmonte E. Physical activity and dementia risk in the elderly: findings from a prospective Italian study. Neurology. 2008;70:1786-1794.

24. Schuit AJ, Feskens EJ, Launer LJ, Kromhout D. Physical activity and cognitive decline, the role of the apolipoprotein e4 allele. Med Sci Sports Exerc. 2001;33:772-777.

25. van Praag H, Shubert T, Zhao C, Gage FH. Exercise enhances learning and hippocampal neurogenesis in aged mice. J Neurosci. 2005;25: $8680-8685$.

26. Nagamatsu LS, Ma H, Hsu T. Resistance training promotes cognitive and functional brain plasticity in seniors with probable mild cognitive impairment. Arch Intern Med. 2012;172:666-668.

27. Nguyen MH, Kruse A. A randomized controlled trial of Tai chi for balance, sleep quality and cognitive performance in elderly Vietnamese. Clin Interv Aging. 2012;7:185-190.

28. Segal SK, Cotman CW, Cahill LF. Exercise-induced noradrenergic activation enhances memory consolidation in both normal aging and patients with amnestic mild cognitive impairment. J Alzheimers Dis. 2012;32:1011-1018.

29. Hoffman B, Blumenthal J, Babyak M, et al. Exercise fails to improve neurocognition in depressed middle-aged and older adults. Med Sci Sports Exerc. 2008;40:1344-1352.

30. Caroni P, Donato F, Muller D. Structural plasticity upon learning: regulation and functions. Nat Rev Neurosci. 2012;13:478-490.

31. DeCarli C, Kawas C, Morrison JH, Reuter-Lorenz PA, Sperling RA, Wright CB. Session II: Mechanisms of age-related cognitive change and targets for intervention: neural circuits, networks, and plasticity. J Gerontol A Biol Sci Med Sci. 2012;67:747-753.

32. Desai AK. Revitalizing the aged-brain. Med Clin North Am. 2011;95: 463-475.

33. Mahncke HW, Connor BB, Appelman J, et al. Memory enhancement in healthy older adults using a brain plasticity-based training program: a randomized, controlled study. Proc Natl Acad Sci U S A. 2006;103:12523-12528.

34. Colcombe SJ, Kramer AF, Erickson KI, et al. Cardiovascular fitness, cortical plasticity, and aging. Proc Natl Acad Sci U S A. 2004;101: 3316-3321.

35. Pang TYC, Hannan AJ. Enhancement of cognitive function in models of brain disease through environmental enrichment and physical activity. Neuropharmacology. 2013;64:515-528.

36. Hall CB, Lipton RB, Sliwinski M, Katz MJ, Derby CA, Verghese J. Cognitive activities delay onset of memory decline in persons who develop dementia. Neurology. 2009;73:365-361.

37. Howes MJ, Perry E. The role of phytochemicals in the treatment and prevention of dementia. Drugs Aging. 2011;28:439-468.

38. Ahlskog JE, Geda YE, Graff-Radford NR, Petersen RC. Physical exercise as a preventive or disease-modifying treatment of dementia and brain aging. Mayo Clin Proc. 2011;86:876-884.

39. Lojovich JM. The relationship between aerobic exercise and cognition: is movement medicinal? J Head Trauma Rehabil. 2010;25:184-192.

40. Ruitenberg A, den Heijer T, Bakker SLM, et al. Cerebral hypoperfusion and clinical onset of dementia: The Rotterdam study. Ann Neurol. 2005;57:789-794.

41. Heran BS, Chen JM, Ebrahim S, et al. Exercise-based cardiac rehabilitation for coronary heart disease. Cochrane Database Syst Rev. 2011;7:CD001800. 
42. Ploughman M. Exercise is brain food: the effects of physical activity on cognitive function. Dev Neurorehabil. 2008;11:236-240.

43. Rhyu IJ, Bytheway JA, Kohler SJ, et al. Effects of aerobic exercise training on cognitive function and cortical vascularity in monkeys. Neuroscience. 2010;167:1239-1248.

44. Erickson KI, Voss MW, Prakash RS, et al. Exercise training increases size of hippocampus and improves memory. Proc Natl Acad Sci USA. 2011;108:3017-3022.

45. Erickson KI, Prakash RS, Voss M, et al. Brain-derived neurotrophic factor is associated with age-related decline in hippocampal volume. J Neurosci. 2010;30:5368-5375.

46. Yamada M, Suzuki K, Kudo S, Totsuka M, Nakaji S, Sugawara K. Raised plasma G-CSF and IL-6 after exercise may play a role in neutrophil mobilization into the circulation. J Appl Physiol (1985). 2002;92:1789-1794.

47. Suzuki K, Yamada M, Kurakake S, et al. Circulating cytokines and hormones with immunosuppressive but neutrophil-priming potentials rise after endurance exercise in humans. Eur J Appl Physiol. 2000;81:281-287.

48. Johnson RA, Rhodes JS, Jeffrey SL, Garland T Jr, Mitchell GS. Hippocampal brain-derived neurotrophic factor but not neurotrophin-3 increases more in mice selected for increased voluntary wheel running. Neuroscience. 2003;121:1-7.

49. Richter-Schmidinger T, Alexopoulos P, Horn M, et al. Influence of brain-derived neurotrophic-factor and apolipoprotein $\mathrm{E}$ genetic variants on hippocampal volume and memory performance in healthy young adults. J Neural Transm. 2011;118:249-257.

50. Webster MJ, Herman MM, Kleinman JE, Shannon Weickert C. BDNF and trkB mRNA expression in the hippocampus and temporal cortex during the human lifespan. Gene Expr Patterns. 2006;6:941-951.

51. Vaynman S, Ying Z, Gomez-Pinilla F. Hippocampal BDNF mediates the efficacy of exercise on synaptic plasticity and cognition. Eur $J$ Neurosci. 2004;20:2580-2590.
52. Borroni B, Bianchi M, Premi E, et al. The brain-derived neurotrophic factor Val66Met polymorphism is associated with reduced hippocampus perfusion in frontotemporal lobar degeneration. J Alzheimers Dis. 2012;31:243-251.

53. Coen RF, Lawlor BA, Kenny R. Failure to demonstrate that memory improvement is due either to aerobic exercise or increased hippocampal volume. Proc Natl Acad Sci U S A. 2011;108:E89.

54. Driscoll I, Martin B, An Y, et al. Plasma BDNF is associated with agerelated white matter atrophy but not with cognitive function in older, non-demented adults. PLoS One. 2012;7:e35217.

55. Larson EB, Wang L, Bowen JD, et al. Exercise is associated with reduced risk for incident dementia among persons 65 years of age and older. Ann Intern Med. 2006;144:73-81.

56. Podewils LJ, Guallar E, Kuller LH, et al. Physical activity, APOE genotype, and dementia risk: findings from the Cardiovascular Health Cognition Study. Am J Epidemiol. 2005;161:639-651.

57. Scarmeas N. Physical activity, diet, and risk of Alzheimer disease. JAMA. 2009;302:627-637.

58. Taaffe DR, Irie F, Masaki KH, et al. Physical activity, physical function, and incident dementia in elderly men: the Honolulu-Asia Aging Study. J Gerontol A Biol Sci Med Sci. 2008;63:529-535.

59. van Gelder BM, Tijhuis MAR, Kalmijn S, Giampaoli S, Nissinen A, Kromhout $\mathrm{D}$. Physical activity in relation to cognitive decline in elderly men: the FINE study. Neurology. 2004;63:2316-2321.

60. Wang L. Performance-based physical function and future dementia in older people. Arch Intern Med. 2006;166:1115-1120.

61. Geda YE, Roberts R, Knopman D, et al. Physical exercise, aging, and mild cognitive impairment: a population-based study. Arch Neurol. 2010;67:80-86.

62. Bixby WR, Spalding TW, Haufler A, et al. The unique relation of physical activity to executive function in older men and women. Med Sci Sports Exerc. 2007;39:1408-1416. 


\section{Supplementary material}

Table SI Agency for Healthcare Research and Quality Methods summary ratings of quality of individual studies

\begin{tabular}{|c|c|}
\hline $\begin{array}{l}\text { Good (low risk } \\
\text { of bias) }\end{array}$ & $\begin{array}{l}\text { These studies have the least bias and results are } \\
\text { considered valid. A study that adheres mostly to the } \\
\text { commonly held concepts of high quality including the } \\
\text { following: a formal randomized controlled design; clear } \\
\text { description of the population, setting, interventions, } \\
\text { and comparison groups; appropriate measurement of } \\
\text { outcomes; appropriate statistical and analytic methods } \\
\text { and reporting; no reporting errors; low dropout rate } \\
\text { and clear reporting of dropouts. }\end{array}$ \\
\hline Fair & $\begin{array}{l}\text { These studies are susceptible to some bias, but it is } \\
\text { not sufficient to invalidate the results. They do not } \\
\text { meet all the criteria required for a rating of good } \\
\text { quality because they have some deficiencies, but } \\
\text { no flaw is likely to cause major bias. The study may } \\
\text { be missing information, making it difficult to assess } \\
\text { limitations and potential problems. }\end{array}$ \\
\hline $\begin{array}{l}\text { Poor (high risk } \\
\text { of bias) }\end{array}$ & $\begin{array}{l}\text { These studies have significant flaws that imply biases } \\
\text { of various types that may invalidate the results. } \\
\text { They have serious errors in design, analysis, or } \\
\text { reporting; large amounts of missing information; } \\
\text { or discrepancies in reporting. }\end{array}$ \\
\hline
\end{tabular}

Source: Agency for Healthcare Research and Quality Methods Reference Guide for Effectiveness and Comparative Effectiveness Reviews (http://www.ahrq.gov/).
Table S2 Characteristics of excluded studies

Andel et al'
Baker et $\mathrm{al}^{2}$
Brownes et $\mathrm{al}^{3}$
Chang et al $\mathrm{al}^{4}$
Colcombe et
Devore et al ${ }^{7}$
Etgen et $\mathrm{al}^{8}$
Fabre et $\mathrm{al}^{9}$
Floel et al

Kasai et $\mathrm{al}^{13}$

Lautenschlager et al ${ }^{14}$

Liu-Ambrose et al ${ }^{15}$

McAuley et al ${ }^{16}$

McAuley et al ${ }^{17}$

Netz et al ${ }^{18}$

O'Dwyer et al ${ }^{19}$

Ojofeitimi et $\mathrm{al}^{20}$

Parekh et $\mathrm{al}^{21}$

Rovio et $\mathrm{al}^{22}$

Rovio et $\mathrm{al}^{23}$

Scherder et $\mathrm{al}^{24}$

Shubert et $\mathrm{a}^{25}$

Vercambre et $\mathrm{al}^{26}$
The study examines the effect of mid-life, not late-life, physical activity on cognition.

Participants were too young to meet the given inclusion criteria of this review.

Participants were too young to meet the given inclusion criteria of this review.

The study contained too few participants and participants were too young to meet the given inclusion criteria of this review.

Examines the effect of mid-life, not late-life, physical activity on cognition.

The study contained too few participants and participants were too young to meet the given inclusion criteria of this review.

Participants were too young to meet the given inclusion criteria of this review.

Participants were too young to meet the given inclusion criteria of this review.

The duration of the study was too short to meet the given inclusion criteria of this review. Participants were too young to meet the given inclusion criteria of this review.

The outcome measure was death; this does not meet the given inclusion criteria for this review. Participants were patients who had suffered traumatic brain injury; this was an exclusion criterion for the review.

The study contained too few participants to meet the given inclusion criteria of this review. Participants were too young to meet the given inclusion criteria of this review.

Participants were elderly patients who had specifically suffered falls; this was an exclusion criterion for the review.

The study contained too few participants and participants were too young to meet the given inclusion criteria of this review.

Outcome measures included social-relation capacity and well-being; this does not meet the given inclusion criteria for this review.

Participants were too young to meet the given inclusion criteria of this review.

The duration of the trial was too short to meet the given inclusion criteria of this review.

Participants were too young to meet the given inclusion criteria for this review.

Participants were patients with lung disease; this was an exclusion criterion for this review. The study examines the effect of mid-life, not late-life, physical activity.

The study examines the effect of mid-life, not late-life, physical activity.

The duration of the trial was too short to meet the given inclusion criteria for this review.

The duration of the trial was too short to meet the given inclusion criteria for this review. Participants were patients specifically with vascular disease; this was an exclusion criterion for the review.

(Continued) 
Table S2 (Continued)

\begin{tabular}{|c|c|}
\hline Verghese et $\mathrm{al}^{27}$ & $\begin{array}{l}\text { The study examines the effect of cognitive, not } \\
\text { physical, leisure activities on late-life cognition. }\end{array}$ \\
\hline $\begin{array}{l}\text { Voelcker-Rehage } \\
\text { et } \mathrm{al}^{28}\end{array}$ & $\begin{array}{l}\text { The study contained too few participants to } \\
\text { meet the given inclusion criteria for this review. }\end{array}$ \\
\hline Weuve et $\mathrm{al}^{29}$ & $\begin{array}{l}\text { Participants were too young to meet the given } \\
\text { inclusion criteria for this review. }\end{array}$ \\
\hline Wolinsky et $\mathrm{al}^{30}$ & $\begin{array}{l}\text { The study examines the effect of cognitive, not } \\
\text { physical, activities on late-life cognition. }\end{array}$ \\
\hline
\end{tabular}

Table S3 Grouping of cognitive tests and studies of cognitive function

\begin{tabular}{|c|c|c|}
\hline Cognitive domain & Name of test & References \\
\hline \multirow[t]{5}{*}{ Cognitive speed } & Simple reaction time & Smiley-Oyen et $\mathrm{al}^{31}$ \\
\hline & 8-Choice reaction time & Smiley-Oyen et $\mathrm{al}^{31}$ \\
\hline & Go/no-go reaction time & Smiley-Oyen et $\mathrm{al}^{31}$ \\
\hline & Digit symbol substitution test & Williamson et $\mathrm{al}^{32}$ \\
\hline & Trail making test & Klusmann et al, ${ }^{33}$ Nguyen et al, ${ }^{34}$ Nagamatsu et $\mathrm{al}^{35}$ \\
\hline Immediate verbal memory & Wechsler Adult Intelligence Scale & Busse et $\mathrm{al}^{36}$ \\
\hline function & The Rey Auditory Verbal Learning Test & Williamson et $\mathrm{al}^{32}$ \\
\hline \multirow[t]{4}{*}{ Global cognitive function } & Mini-Mental State Examination & Lytle et al, ${ }^{37}$ Miu et al, ${ }^{38}$ Muscari et al, ${ }^{39}$ \\
\hline & Modified Mini-Mental State Examination & Ravaglia et al, ${ }^{40}$ Schuit et al, ${ }^{41}$ Van Gelder et al, ${ }^{42}$ \\
\hline & & Williamson et $\mathrm{al}^{32}$ Laurin et $\mathrm{al}^{43}{ }^{43}$ Klusmann et $\mathrm{al}^{33}$ \\
\hline & & Middleton et al, ${ }^{44}$ Podewils et $a l,{ }^{45}$ Yaffe et al ${ }^{46}$ \\
\hline \multirow[t]{2}{*}{ Cognitive inhibition } & Stroop Color and Word Test & Bixby et al, ${ }^{47}$ Smiley-Oyen et al, ${ }^{31}$ \\
\hline & & Williamson et al, ${ }^{32}$ Nagamatsu et $\mathrm{al}^{35}$ \\
\hline \multirow[t]{3}{*}{ Working memory } & Direct and Indirect Digit Span & Busse et $\mathrm{al}^{36}$ \\
\hline & Rivermead Behavioral Memory Test & Busse et $\mathrm{al}^{36}$ \\
\hline & Memory Complaints Scale & Cassilhas et $\mathrm{al}^{48}$ Busse et $\mathrm{al}^{36}$ \\
\hline $\begin{array}{l}\text { Differentiation between dementia } \\
\text { and Alzheimer's disease }\end{array}$ & Cambridge Cognitive Test & Busse et $\mathrm{al}^{36}$ \\
\hline Verbal/nonverbal intelligence & Kaufman Brief Intelligence Test & Bixby et al $^{47}$ \\
\hline Sustained attention & Toulouse-Pieron Concentration Attention Test & Cassilhas et $\mathrm{al}^{48}$ \\
\hline \multirow[t]{3}{*}{ Presence of dementia } & Cognitive Abilities Screening Instrument & Taaffe et al, ${ }^{49}$ Wang et $a^{51}$ \\
\hline & Informant Questionnaire on Cognitive Decline in the Elderly & Taaffe et $\mathrm{al}^{49}$ \\
\hline & Community Screening for Dementia & Wang et $\mathrm{al}^{50}$ \\
\hline \multirow[t]{2}{*}{ Presence of Alzheimer's disease } & Alzheimer's Disease Assessment Scale-Cognitive Subscale & Miu et $\mathrm{al}^{38}$ \\
\hline & Mental Deterioration Battery & Ravaglia et $\mathrm{al}^{40}$ \\
\hline \multirow[t]{2}{*}{ Executive function } & Wisconsin Card Sort Test & Smiley-Oyen et $\mathrm{al}^{31}$ \\
\hline & Rey-Osterrieth Complex Figure Test & Williamson et $\mathrm{al}^{32}{ }^{32}$ Wang et $\mathrm{al}^{51}$ \\
\hline
\end{tabular}




\section{References}

1. Andel R, Crowe M, Pedersen NL, Fratiglioni L, Johansson B, Gatz M. Physical exercise at midlife and risk of dementia three decades later: a population-based study of Swedish twins. J Gerontol A Biol Sci Med Sci. 2008;63(1):62-66.

2. Baker LD, Frank LL, Foster-Schubert K. Effects of aerobic exercise on mild cognitive impairment: a controlled trial. Arch Neurol. 2010;67(1):71-79.

3. Barnes DE, Yaffe K, Satariano WA, Tager IB. A longitudinal study of cardiorespiratory fitness and cognitive function in healthy older adults. J Am Geriatr Soc. 2003;51:459-465.

4. Brown AD, McMorris CA, Longman RS, et al. Effects of cardiorespiratory fitness and cerebral blood flow on cognitive outcomes in older women. Neurobiol Aging. 2010;31:2047-2057.

5. Chang M, Jonsson PV, Snaedal J, et al. The effect of midlife physical activity on cognitive function among older adults: AGES-Reykjavik Study. J Gerontol A Biol Sci Med Sci. 2010;65:1369-1374.

6. Colcombe SJ, Kramer AF, Erickson KI, et al. Cardiovascular fitness, cortical plasticity, and aging. Proc Natl Acad Sci USA. 2004; 101:3316-3321.

7. Devore EE, Kang JH, Okereke O, Grodstein F. Physical activity levels and cognition in women with type 2 diabetes. Am J Epidemiol. 2009;170:1040-1047.

8. Etgen T, Sander D, Huntgeburth U, Poppert H, Forstl H, Bickel H. Physical activity and incident cognitive impairment in elderly persons: the INVADE study. Arch Intern Med. 2010;170:186-193.

9. Fabre C, Chamari K, Mucci P, Masse-Biron J, Prefaut C. Improvement of cognitive function by mental and/or individualized aerobic training in healthy elderly subjects. International Journal of Sports Medicine 2002;23:415-421.

10. Floel A, Ruscheweyh R, Kruger K, et al. Physical activity and memory functions: are neurotrophins and cerebral gray matter volume the missing link? NeuroImage. 2010;49:2756-2763.

11. Gillum RF, Obisesan TO. Physical activity, cognitive function, and mortality in a US national cohort. Ann Epidemiol. 2010;20:251-257.

12. Hassett LM, Moseley AM, Tate R, Harmer AR. Fitness training for cardiorespiratory conditioning after traumatic brain injury. Cochrane Database Syst Rev. 2008;CD006123.

13. Kasai JYT, Busse AL, Magaldi RM, et al. Effects of Tai Chi Chuan on cognition of elderly women with mild cognitive impairment. Einstein (16794508) 2010;8:40-45.

14. Lautenschlager NT, Cox KL, Flicker L, et al. Effect of physical activity on cognitive function in older adults at risk for Alzheimer disease: a randomized trial. JAMA. 2008;300:1027-1037.

15. Liu-Ambrose T, Donaldson MG, Ahamed Y, et al. Otago home-based strength and balance retraining improves executive functioning in older fallers: a randomized controlled trial. $J$ Am Geriatr Soc. 2008;56:1821-1830.

16. McAuley E, Szabo AN, Mailey EL, et al. Non-exercise estimated cardiorespiratory fitness: associations with brain structure, cognition, and memory complaints in older adults. Ment Health Phys Act. 2011; $4: 5-11$.

17. McAuley E, Blissmer B, Marquez DX, Jerome GJ, Kramer AF, Katula J. Social relations, physical activity, and well-being in older adults. Prev Med. 2000;31:608-617.

18. Netz Y, Argov E, Inbar O. Fitness's moderation of the facilitative effect of acute exercise on cognitive flexibility in older women. J Aging Phys Act. 2009;17:154-166.

19. O'Dwyer ST, Burton NW, Pachana NA, Brown WJ. Protocol for Fit Bodies, Fine Minds: a randomized controlled trial on the affect of exercise and cognitive training on cognitive functioning in older adults. BMC Geriatr. 2007;7:23.

20. Ojofeitimi EO, Ijadunola KT, Jegede VA, et al. Nutritional status and physical activity in relation to cognitive function in a group of elderly in Nigeria. Journal of Nutrition For the Elderly. 2002;22:49-62.
21. Parekh PI, Blumenthal JA, Babyak MA, et al. Gas exchange and exercise capacity affect neurocognitive performance in patients with lung disease. Psychosom Med. 2005;67:425-432.

22. Rovio S, Kåreholt I, Helkala EL, et al. Leisure-time physical activity at midlife and the risk of dementia and Alzheimer's disease. Lancet Neurol. 2005;4:705-711.

23. Rovio S, Kåreholt I, Viitanen M, et al. Work-related physical activity and the risk of dementia and Alzheimer's disease. Int J Geriatr Psychiatry. 2007;22:874-882.

24. Scherder EJ, Van Paasschen J, Deijen JB, et al. Physical activity and executive functions in the elderly with mild cognitive impairment. Aging Ment Health. 2005;9:272-280.

25. Shubert TE, McCulloch K, Hartman M, Giuliani CA. The effect of an exercise-based balance intervention on physical and cognitive performance for older adults: a pilot study. J Geriatr Phys Ther. 2010;33:157-164.

26. Vercambre MN, Grodstein F, Manson JE, Stampfer MJ, Kang JH. Physical activity and cognition in women with vascular conditions. Arch Intern Med. 2011;171:1244-1250.

27. Verghese J, Lipton RB, Katz MJ, et al. Leisure activities and the risk of dementia in the elderly. N Engl J Med. 2003;348:2508-2516.

28. Voelcker-Rehage C, Godde B, Staudinger UM. Physical and motor fitness are both related to cognition in old age. Euro J Neurosci. 2010;31:167-176.

29. Weuve J, Kang JH, Manson JE, Breteler MM, Ware JH, Grodstein F. Physical activity, including walking, and cognitive function in older women. JAMA. 2004;292:1454-1461.

30. Wolinsky FD, Unverzagt FW, Smith DM, Jones R, Wright E, Tennstedt SL. The effects of the ACTIVE cognitive training trial on clinically relevant declines in health-related quality of life. J Gerontol B Psychol Sci Soc Sci. 2006;61:S281-S287.

31. Smiley-Oyen AL, Lowry KA, Francois SJ, Kohut ML, Ekkekakis P. Exercise, fitness, and neurocognitive function in older adults: the "selective improvement" and "cardiovascular fitness" hypotheses. Ann Behav Med. 2008;36:280-291.

32. Williamson JD, Espeland M, Kritchevsky SB, et al. Changes in cognitive function in a randomized trial of physical activity: results of the lifestyle interventions and independence for elders pilot study. J Gerontol A Biol Sci Med Sci. 2009;64:688-694.

33. Klusmann V, Evers A, Schwarzer R, et al. Complex mental and physical activity in older women and cognitive performance: a 6-month randomized controlled trial. J Gerontol A Biol Sci Med Sci. 2010;65:680-688.

34. Nguyen MH, Kruse A. A randomized controlled trial of Tai chi for balance, sleep quality and cognitive performance in elderly Vietnamese. Clin Interv Aging. 2012;7:185-190.

35. Nagamatsu LS, Handy TC, Hsu CL, Voss M, Liu-Ambrose T. Resistance training promotes cognitive and functional brain plasticity in seniors with probable mild cognitive impairment. Arch Intern Med. 2012; 172:666-668.

36. Busse AL, Filho WJ, Magaldi RM, et al. Effects of resistance training exercise on cognitive performance in elderly individuals with memory impairment: results of a controlled trial. Einstein. 2008;6:402-407.

37. Lytle ME, Vander Bilt J, Pandav RS, Dodge HH, Ganguli M. Exercise level and cognitive decline: the MoVIES project. Alzheimer Dis Assoc Disord. 2004;18:57-64.

38. Miu DKY, Szeto SL, Mak YF. A randomized controlled trial on the effect of exercise on physical, cognitive, and affective function in dementia subjects. Asian J Gerontol Geriatr. 2008;3:8-16.

39. Muscari A, Giannoni C, Pierpaoli L, et al. Chronic endurance exercise training prevents aging-related cognitive decline in healthy older adults: a randomized controlled trial. Int J Geriatr Psychiatry. 2010;25:1055-1064.

40. Ravaglia G, Forti P, Lucicesare A, et al. Physical activity and dementia risk in the elderly: findings from a prospective Italian study. Neurology. 2008;70:1786-1794. 
41. Schuit AJ, Feskens EJ, Launer LJ, Kromhout D. Physical activity and cognitive decline, the role of the apolipoprotein e4 allele. Med Sci Sports Exerc. 2001;33:772-777.

42. van Gelder BM, Tijhuis MA, Kalmijn S, Giampaoli S, Nissinen A, Kromhout D. Physical activity in relation to cognitive decline in elderly men: the FINE Study. Neurology. 2004;63:2316-2321.

43. Laurin D, Verreault R, Lindsay J, MacPherson K, Rockwood K. Physical activity and risk of cognitive impairment and dementia in elderly persons. Arch Neurol. 2001;58:498-504.

44. Middleton LE, Manini TM, Simonsick EM, et al. Activity energy expenditure and incident cognitive impairment in older adults. Arch Intern Med. 2011;171:1251-1257.

45. Podewils LJ, Guallar E, Kuller LH, et al. Physical activity, APOE genotype, and dementia risk: findings from the Cardiovascular Health Cognition Study. Am J Epidemiol. 2005;161:639-651.

46. Yaffe K. A prospective study of physical activity and cognitive decline in elderly women: Women who walk. Archives of Internal Medicine 2001;161:1703-1708.
47. Bixby WR, Spalding TW, Haufler AJ, et al. The unique relation of physical activity to executive function in older men and women. Med Sci Sports Exerc. 2007;39:1408-1416.

48. Cassilhas RC, Viana VA, Grassmann V, et al. The impact of resistance exercise on the cognitive function of the elderly. Med Sci Sports Exerc. 2007;39:1401-1407.

49. Taaffe DR, Irie F, Masaki KH, et al. Physical activity, physical function, and incident dementia in elderly men: the Honolulu-Asia Aging Study. J Gerontol A Biol Sci Med Sci. 2008;63:529-535.

50. Wang L, Larson EB, Bowen JD, van Belle G. Performance-based physical function and future dementia in older people. Arch Intern Med. 2006;166:1115-1120.

51. Wang HX, Jin Y, Hendrie HC, et al. Late life leisure activities and risk of cognitive decline. J Gerontol A Biol Sci Med Sci. 2013;68:205-213.
Clinical Interventions in Aging

\section{Publish your work in this journal}

Clinical Interventions in Aging is an international, peer-reviewed journal focusing on evidence-based reports on the value or lack thereof of treatments intended to prevent or delay the onset of maladaptive correlates of aging in human beings. This journal is indexed on PubMed Central, MedLine, the American Chemical Society's 'Chemical Abstracts

\section{Dovepress}

Service' (CAS), Scopus and the Elsevier Bibliographic databases. The manuscript management system is completely online and includes a very quick and fair peer-review system, which is all easy to use. Visit http://www.dovepress.com/testimonials.php to read real quotes from published authors. 